\title{
Cell adhesion on nanopatterned fibronectin substrates
}

\author{
Dan Liu, Che Azurahanim Che Abdullah, Richard P. Sear and Joseph L. Keddie
}

Department of Physics and Surrey Materials Institute, University of Surrey, Guildford, Surrey, United Kingdom GU2 7XH

\begin{abstract}
:
\end{abstract}
The coating of substrates with an extracellular matrix (ECM) protein, such as fibronectin (FN), is often employed to increase cell adhesion and growth. Here, we examine the influence of the size scale and geometry of novel FN nanopatterns on the adhesion and spreading of Chinese Hamster Ovary (CHO) cells. The FN is patterned on the surface of templates created through the self-assembly of polystyrene-blockpolyisoprene (PS-b-PI) diblock copolymers. Both ring-like and stripe-like FN nanopatterns are created through the preferential adsorption of FN on PS blocks, as confirmed through the complementary use of atomic force microscopy and secondary ion mass spectrometry. The ring-like FN nanopattern substrate increases the cells' adhesion compared with the cells on homogeneous FN surfaces and the stripe-like FN nanopatterns. Cell adhesion is high when the FN ring size is greater than $50 \mathrm{~nm}$ and when the surface coverage of $\mathrm{FN}$ is less than $c a .85 \%$. We suggest that the ring-like nanopatterns of FN may be aiding cell adhesion by increasing the clustering of the proteins (integrins) with which cells bind to the nanopatterned substrate. This clustering is required for cell adhesion. In comparison to lithographic techniques, the FN templating method, presented here, provides a simple, convenient and economical way of coating substrates for tissue cultures and should be applicable to tissue engineering. 


\section{Introduction}

To grow, cells of most types need to adhere to something. In vivo, the substrate is the extracellular matrix $(\mathrm{ECM})$ or other cells ${ }^{1}$. Thus, to encourage cell growth for tissue engineering ${ }^{2,3}$ we need to provide substrates that mimic at least some properties of the ECM. Interactions with the ECM, or with artificial mimics of it, play a crucial role in fundamental cellular functions, including cell migration, ${ }^{4,5}$ proliferation, ${ }^{6,7}$ differentiation, ${ }^{8}$ and apoptosis. ${ }^{9,10}$

Cell adhesion is mediated by specific protein receptors, known as integrins, on the cell surface. They interact with ECM molecules. These trans-membrane receptors have extracellular domains that bind to the ECM and intracellular domains that link to the cytoskeleton. ${ }^{11}$ Upon ligand binding, integrins undergo a conformational change that leads to the recruitment of cytoplasmic "anchor proteins," such as vinculin, talin and paxillin, which bind the actin cytoskeleton to the membrane. Through physical clustering of multiple integrins, more cytoplasmic proteins are recruited to the adhesion site to increase its size, adhesion strength, and biochemical signalling activity. ${ }^{12,13}$ These larger, clustered structures of integrins and cytoplasmic proteins, which are 100s of nm across, are commonly called focal adhesions. They function as crucial outside-to-inside signalling ports and help cells to function properly.

Integrins are approximately $10 \mathrm{~nm}$ across, and work by the group of Spatz ${ }^{14}$ has found that spacing their ligands more than $58 \mathrm{~nm}$ apart greatly reduces cell adhesion. Thus we expect that engineering the surface on a lengthscale of 10 s of nanometres can control and enhance cell adhesion..

For the binding interactions between cells and surfaces, it has become increasingly evident that cells detect and respond to numerous features of the ECM, 
including the structural composition and availability of adhesive ligands, ${ }^{15,16}$ mechanical stiffness ${ }^{17}$ spatial organization of cell recognition sites, ${ }^{18,19}$ and surface topography of these ECM scaffolds at the microscale and nanoscale. ${ }^{20,21,22}$ The importance of the structural organization of focal adhesions on a molecular length scale has been demonstrated by investigations of cellular responses to the lateral spacing of adhesion-associated ligands (such as ECM proteins). ${ }^{23}$ The nanometre- and micrometre-scale organization of surface proteins is expected to play a crucial role in focal adhesion formation and hence on cell behaviour.

Cell adhesion and cellular organization have been widely studied as a function of the available adhesive area and shape on a substrate using micrometer-scale patterns. ${ }^{24,25}$ However, a key event in focal adhesion assembly is the activation and clustering of ligand-occupied integrins. Patterning methods at the length-scale of tens of nanometres are required to explore how integrin-mediated cell adhesion depends not only on receptor occupancy but also on receptor clustering. With the control of integrin receptor clustering, substrates patterned with ligands at the nanoscale level are suitable for addressing this aspect of cell-ECM interactions. Recently, there has been considerable work on cell behaviour on nanopatterned substrates of ECM proteins $^{26,27}$ or particular ECM sequences ${ }^{14,28}$ (e.g. arginine-glycine-aspatate (RGD)). Such ECM patterns were created using techniques of lithography via a procedure that is multi-step and not available in all laboratories.

In vitro studies of well-defined templates of ECM molecules allow studies of cell adhesion, spreading, growth, differentiation and functioning. Templates have been fabricated through controlling the placement of whole ECM molecules (or moieties present in the ECM to which integrins bind) on the surface. These nano- or 
micro-arrayed regions that encourage integrin binding are surrounded by nonadhesive regions, which typically resist cell adhesion by resisting the adsorption of protein. Protein surface patterning can be realized through various approaches such as microcontact printing, ${ }^{29}$ dip-pen lithography, ${ }^{30}$ electron beam lithography, ${ }^{31}$ and selfassembly. $^{32}$ As an example of self-assembly, a patterning method using block copolymer nanolithography (BCN) has been developed recently. This technique is based on the self-assembly driven deposition of spherical micelles on solid substrates. By using diblock copolymers of different molecular weight, the separation distance between spherical minority phases can be tuned. ${ }^{32}$

In the present work, a very simple method was used to pattern protein molecules. A self-assembled diblock copolymer substrate, made from polystyreneblock-polyisoprene, was used as a template to form protein nanopatterns through the protein selective adsorption on the polystyrene domain. We have previously shown ${ }^{33}$ that another protein (bovine serum albumin) selectively adsorbs on glassy PS domains and forms nanopatterned structures resembling the underlying copolymer templates. The ECM protein, FN, was adsorbed on our copolymer templates to form nanopatterned FN substrates. By comparing the cell adhesion phenomena on nanopatterned FN surfaces with varying length scales, we determine how surface patterning and organization at the nanoscale level of the ECM affects cell adhesion and spreading.

In the preparation of cell and tissue cultures, $\mathrm{FN}$ or similar proteins are often attached to polymer substrates to aid cell growth. The polymer surface is functionalized through a plasma treatment, e.g. low-temperature plasmas ${ }^{34,35}$ and either low-pressure glow discharges ${ }^{36}$ or atmospheric-pressure ("corona") 
discharges. ${ }^{34,35,36}$ Proteins are attached to plasma-treated surfaces to create a uniform and homogeneous layer. By comparison, the method presented here is simpler, more economical and able to be implemented in most laboratories. More importantly, the proteins are deposited in a nanopattern that aids cell attachment and spreading.

\section{Experimental Details}

\section{FN nanopattern fabrication}

Si (100) wafers and glass coverslips were cleaned using a UV-ozone cleaner before being used as substrates. Because of its optical reflectivity, Si was the substrate for all ellipsometry measurements. Because of its rigidity, it was also used as the substrate material in all atomic force microscopy experiments. Confocal microscopy requires the use of optically transparent substrates, and hence glass coverslips were used. Both materials were used as substrates for contact angle analysis.

Polystyrene (PS, number average molecular weight, $M_{\mathrm{n}}=257.9 \mathrm{~kg} / \mathrm{mol}$ ), polyisoprene (PI, $M_{\mathrm{n}}=100 \mathrm{~kg} / \mathrm{mol}$ ), and PS- $b$-PI diblock copolymer (purchased from Polymer Source) were used as received. Two copolymers, both with a total $M_{n}=91$ $\mathrm{kg} / \mathrm{mol}$ but different ratios of the two blocks, were selected as a means to vary the nanostructure. One symmetric PS- $b$-PI possesses a PS component with $M_{n}=45$ $\mathrm{kg} / \mathrm{mol}$ and PI component with $M_{n}=46 \mathrm{~kg} / \mathrm{mol}$. It is represented here as PS(45)- $b$ PI(46). Another asymmetric PS- $b$-PI has a PS component with $M_{n}=65 \mathrm{~kg} / \mathrm{mol}$ and a PI component with $M_{n}=26 \mathrm{~kg} / \mathrm{mol}$. It is described here as PS(65)- $b$-PI(26). Polymer solutions in toluene (reagent grade, Sigma-Aldrich, UK) were spin-cast onto cleaned Si (100) or glass substrates with a spin rate of $2000 \mathrm{rpm}$. The thicknesses of the asspun films were measured with spectroscopic ellipsometry (VASE, J.A. Woollam Co., Inc. Lincoln, NE, USA). Films were not annealed after casting, in order to preserve 
their non-equilibrium structures. ${ }^{33}$ Homogeneous and nanopatterned polymer templates were fabricated for protein adsorption using homopolymers (PS and PI) and PS- $b$-PI, respectively.

FN (from bovine plasma, $1.2 \mathrm{mg} / \mathrm{ml}$ sterile solution, cell culture tested (Sigma-Aldrich, Product No. F1141)) was diluted in a universal buffer (150 mM $\mathrm{NaCl}, 50 \mathrm{mM}$ Tris- $\mathrm{HCl}, \mathrm{pH} 7.5)$ to $50 \mu \mathrm{g} / \mathrm{ml}$. The polymer-coated, $\mathrm{Si}$ and glass substrates were incubated with FN solution for one hour at room temperature. PI films were only incubated for $10 \mathrm{~min}$. because they are subject to dewetting at longer times. Upon removal from the FN solution, the samples were rinsed thoroughly with flowing Tris buffer solution followed by DI water to remove non-adsorbed FN molecules and residual salt from the buffer, respectively. The samples were dried in a desiccator (containing silica gel) for $24 \mathrm{hr}$ prior to surface analysis. The procedures were the same for both Si and glass substrates.

\section{FN surface imaging and characterization}

Atomic force microscopy (AFM) was performed in the intermittent-contact mode of a commercial instrument (NTEGRA, NT-MDT, Moscow, Russia) using a gold-coated silicon cantilever (NT-MDT) with a nominal spring constant ranging from 5 to $10 \mathrm{~N} / \mathrm{m}$ and a resonant frequency ranging from 130 to $180 \mathrm{kHz}$. All the AFM experiments were performed in air at room temperature, and the images were captured using a scan speed of $1.2 \mathrm{~Hz}$.

Time-of-flight secondary ion mass spectroscopy (ToF-SIMS) was employed to characterize the relative intensity of surface components before and after the FN adsorption. ToF-SIMS analysis was carried out on an ION-TOF GmbH (Münster, 
Germany) TOF-SIMS 5 system. The instrument is equipped with a reflection type analyser and a microchannel detector. Data acquisition was performed by raster scanning the $\mathrm{Bi}^{3+}$ primary ion beam over a $100 \mu \mathrm{m} \times 100 \mu \mathrm{m}$ area at a resolution of 64 pixels $\times 64$ pixels. Every sample was probed three times in three different areas, and averages are reported. The probe depth was around 10-20 $\AA$ from the film surfaces. The positive and negative ions from the sample's outermost surfaces were collected and converted to the $\mathrm{m} / \mathrm{z}=0-500$ mass spectra.

Water contact angle analysis (WCAA) was performed with a commercial instrument (Easy Drop, Krüss $\mathrm{GmbH}$, Germany) and used to measure the relative surface hydrophilicity at different areas, which were selected before cell incubation. A $3 \times 3$ grid was drawn in permanent ink on the underside of the glass substrate to divide the substrate into nine sub-areas. In this approach, the water contact angle in a particular sub-area could be correlated with the cell adhesion at that same position. A $1 \mu \mathrm{l}$ drop of DI water was deposited onto the sample surface. For every sub-area of a sample, three drops were deposited, and the average value was obtained.

\section{Cell cultures}

Chinese Hamster Ovary (CHO) cells (Cat No: 85050302) with epithelial morphology were purchased from European Collection of Cell Cultures (ECACC). Protocols established by ECACC for the culture and passage of Chinese Hamster Ovary $(\mathrm{CHO})$ cells were followed. ${ }^{37}$ Cells were cultured in tissue culture flasks (75 $\mathrm{cm}^{2}$ ) in a humidified atmosphere at $37{ }^{\circ} \mathrm{C}$ with $5 \% \mathrm{CO}_{2}$ (by volume). The cells were grown in F-12 Ham's medium (Invitrogen) supplemented with 10\% (by volume) foetal bovine serum (Gibco) and $1 \%$ (by volume) of antibiotics (penicillin/streptomycin) as a prophylactic measure against bacterial infection. 
Cultures were passaged every 48 hours by a dilution factor of $1 / 6$ or every 72 hours by a dilution factor of $1 / 7$. After the cells reached confluence, they were first rinsed with sterile phosphate buffer saline (PBS) solution and then detached from the flask wall by incubating with $0.05 \%$ of trypsin-EDTA (purchased from Gibco) solution for 3-5 min. in a warm water bath.. For seeding samples, culture flasks (75 $\mathrm{cm}^{2}$ growth area) of $80 \%$ confluent $\mathrm{CHO}$ cells were trypsinized, washed and suspended in fresh media. The suspension of cells was then diluted with cell growth media to the desired cell concentration. Cell suspensions were then added to polystyrene Petri dishes (13 mm diameter) containing prepared FN substrates on glass and incubated for one hour. For microscopy and imaging experiments, the cell plating density was $1000-1500$ cells $/ \mathrm{mm}^{2}$.

\section{Fixing and staining cells}

The cell-seeded substrates were then washed with PBS and fixed with $4 \%$ paraformaldehyde in PBS for 20 min. After fixation, the samples were rinsed gently with PBS and permeabilized with $0.1 \%$ non-ionic surfactant (Triton X, Sigma) in PBS for 5 min. Samples were then thoroughly washed with PBS and stained. Samples were incubated with phalloidin (1:300 dilution, AlexaFluor phalloidin, Molecular Probes, Eugene, OR) for $30 \mathrm{~min}$. at room temperature. After rinsing with PBS, samples were subsequently incubated with DRAQ5 (BD Biosciences Limited) for $10 \mathrm{~min}$. at room temperature. Stained cells were mounted with a coverslip in Vectashield mounting medium (Vector Laboratories, Inc., Burlingame, CA) and sealed with nail varnish. Double-labelled samples were examined via confocal microscopy (Zeiss LSM 510).

\section{Microscopy and image acquisition}

Imaging was conducted by using a Zeiss LSM 510 META laser scanning 
confocal microscope. For doubly-stained cells, phalloidin (actin stain) was excited with the argon laser line at $488 \mathrm{~nm}$ and DRAQ5 (nucleus counterstain) with the helium-neon laser line at $633 \mathrm{~nm}$. The emission signals passed through 505-530 nm and 649-799 nm filters, respectively. All images were captured with a PlanApochromat 40x/1.4 oil and Plan-Apochromat 63x/1.4 oil DIC objective and collected in multichannel mode.

\section{Image analysis}

Cell morphology on each test substrate was quantified using image analysis software, IMAGE J (version 1.42), from the United States National Institutes of Health (http://rsb.info.nih.gov/ij/). IMAGE $\mathrm{J}$ automatically detects the cell outline and calculates parameters such as the number of cells, cell area, and coverage per unit area of the substrate. The dimensions were calibrated using a stage micrometer.

\section{Results and Discussion}

\section{FN nanopattern imaging and characterization}

AFM images of the surface structures of PS, PS(45)- $b$-PI(46), and PS(65)- $b$ PI(26) films have been shown in our previous work. ${ }^{33}$ The surface structures of the PS(45)- $b$-PI(46), and PS(65)-b-PI(26) copolymer films with a thickness of $c a .18 \mathrm{~nm}$ are dot-like and stripe-like nanopatterns, respectively. Representative AFM images of the original copolymer surfaces (on Si substrates) are shown in Figure S1 in the Supplementary Data. AFM images of PS and PS- $b$-PI substrates after the adsorption of FN are shown in Fig. 1. After comparing these images to those from the original surfaces, our preliminary interpretation is that FN molecules appear to cover fully the PS surface and create a dense and uniform carpet (Fig. 1a and 1b).

On the stripe-like copolymer template obtained from PS(65)-b-PI(26), it 
appears that the FN molecules also form a stripe-like nanopattern resembling the underlying copolymer structure (Fig. 1c and 1d). As was also found on the original copolymer surface, there is a strong contrast in the height and phase images. At room temperature, the PI block is above its glass transition temperature and is a viscous liquid. It appears darker in the phase image, because the AFM dissipates more energy when contacting it in comparison to the glassy PS block. ${ }^{33}$ AFM measurements of the peak-to-valley height before and after the FN incubation find that the height difference increases by $2.5 \mathrm{~nm}$ as a result of the $\mathrm{FN}$ incubation. This increase in height can be explained by the preferential adsorption of a monolayer of FN on the PS blocks, as was found previously in the case of BSA. ${ }^{33}$ On the dot-like PS(45)- $b$-PI(46) copolymer surface, the FN forms a ring-like network structure (Fig. 1e and 1f). This interpretation is explained by the selective adsorption of FN on PS domains and exclusion from the dot domains of PI. The feature size of this nanopattern is $c a .50$ $\mathrm{nm}$, which is larger than the size of the stripe-like pattern.
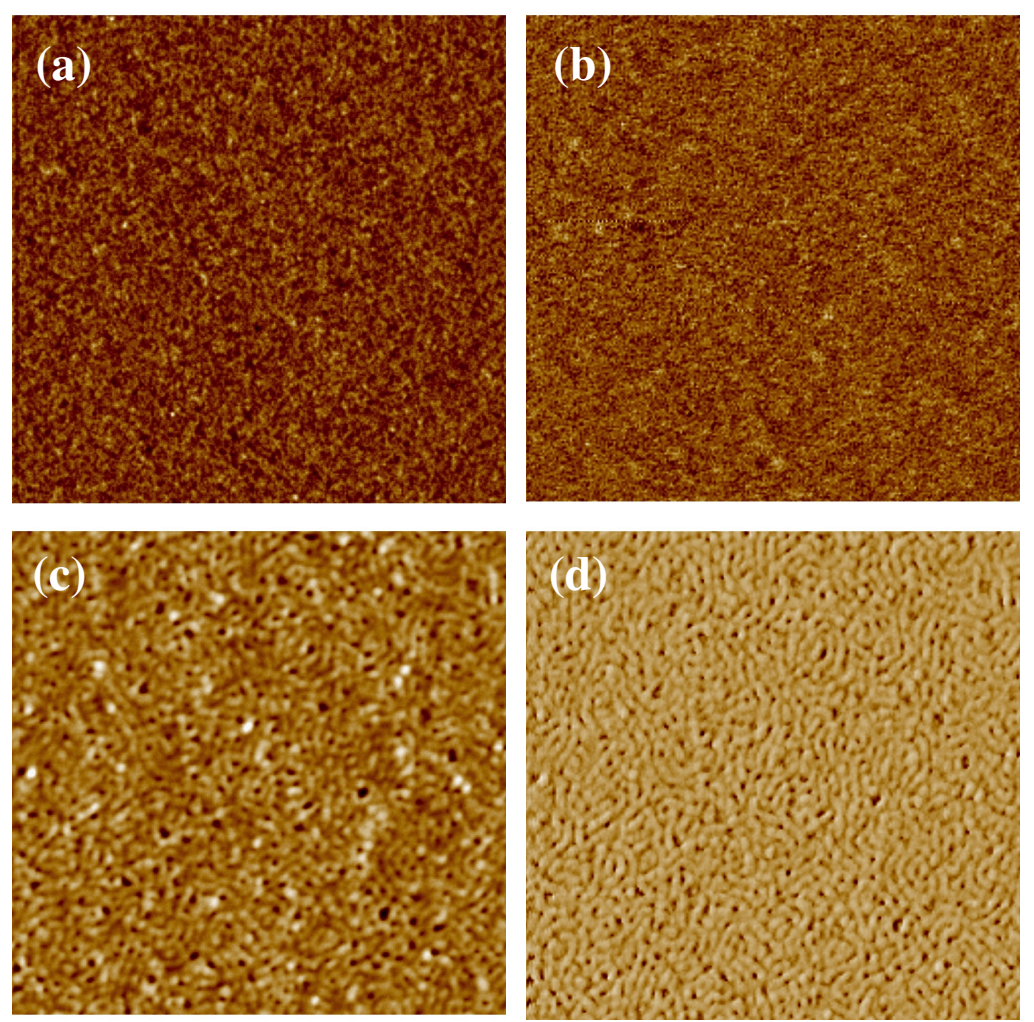

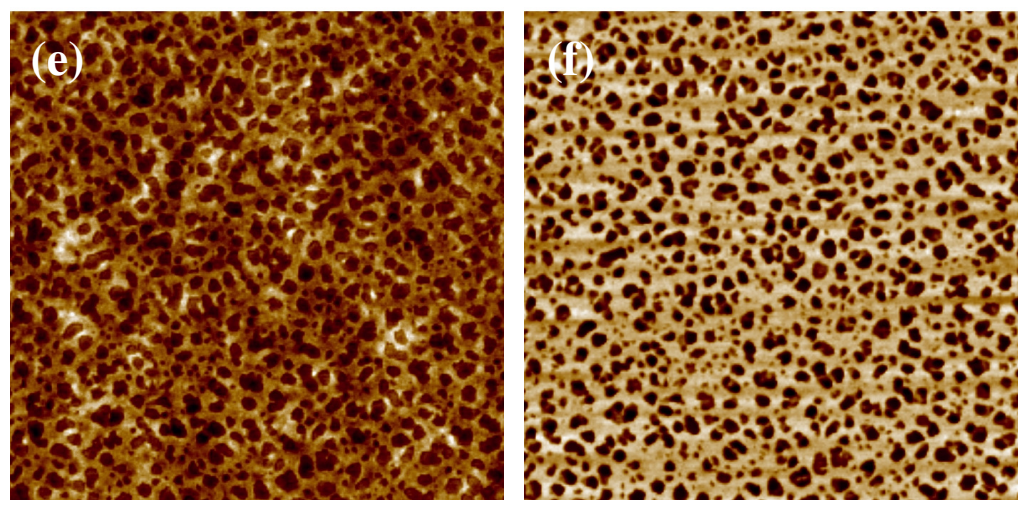

Fig. 1 AFM (a) height and (b) phase images of a PS film after FN incubation for 1h; AFM (c) height and (d) phase images of a $17.8 \mathrm{~nm}$ PS(65)- $b$-PI(26) film after FN incubation; and AFM (e) height and (f) phase images of a $17.7 \mathrm{~nm}$ PS(45)- $b$-PI(46) film after FN incubation. Image sizes are $2 \mu \mathrm{m} \times 2 \mu \mathrm{m}$.

To verify this interpretation of the AFM images, the surfaces of dense FN layers and FN on polymer templates were analyzed by ToF-SIMS. (Identical samples were used for the two techniques.) Both positive and negative ion spectra were collected, but only the positive spectra were used for analysis because of their greater discriminating ability. FN has unique peaks corresponding to nitrogen-containing fragments at $m / z=18,30,44,60,70$ and $86 \mathrm{u}$, which present the characteristic ion fragments dislodged from some specific amino acids in the FN chain. These peaks are not found in the spectra of PS- $b$-PI hydrocarbon polymer fragments and can be used to quantify the FN and to differentiate it from the underlying polymer components. For each fragment, the relative peak intensity (RPI) is determined by the dividing the number of counts by the total number of counts in the entire spectrum.

Table 1 gives the summed RPI of the characteristic FN peaks on each polymer sample after protein adsorption. The summed RPI of FN on the PS substrate is $109 \times 10^{-3}$. The FN's RPI value on PS(65)- $b$-PI(26) substrate is only $9 \times 10^{-3}$ less than that found on PS. This is because the stripe-like PS(65)- $b$-PI(26) substrate was 
densely covered by FN molecules. The dot-like PS(45)- $b$-PI(46) substrate has a lower PS component on its surface. After FN adsorption, the RPI of FN is about $80 \times 10^{-3}$ and it is significantly less than the value on the stripe-like pattern. This means that the coverage percentage of FN on PS(45)- $b$-PI(46) substrate is less than that on PS(65)- $b$ PI(26) substrate. This conclusion is consistent with the previously-presented interpretation of the AFM images. The pure $350 \mathrm{~nm}$ thick PI sample also adsorbed a few FN molecules after only 10 min of incubation, but less than any thin copolymer samples.

Table 1 Relative peak intensities of characteristic fibronectin (FN) ion peaks on homogeneous and nanopatterned substrates.

\begin{tabular}{|c|c|c|c|c|}
\hline & \multicolumn{4}{|c|}{ Relative Peak Intensities (x 10 $\left.0^{-3}\right)$} \\
\hline $\begin{array}{c}\text { FN peaks } \\
(\mathrm{m} / \mathrm{z})\end{array}$ & $\begin{array}{c}\text { FN on PS } \\
(1 \mathrm{~h} \\
\text { incubation })\end{array}$ & $\begin{array}{c}\text { FN on PS(65)- } b- \\
\text { PI(26) }(1 \mathrm{~h} \\
\text { incubation })\end{array}$ & $\begin{array}{c}\text { FN on PS(45)- } b- \\
\text { PI(46) }(1 \mathrm{~h} \\
\text { incubation) }\end{array}$ & $\begin{array}{c}\text { FN on PI (10 } \\
\text { min incubation) }\end{array}$ \\
\hline 18 & $6.9 \pm 0.2$ & $6.7 \pm 0.2$ & $5.6 \pm 0.08$ & $0.9 \pm 0.01$ \\
\hline 30 & $29.5 \pm 0.5$ & $29.6 \pm 1.2$ & $20.3 \pm 0.4$ & $6.1 \pm 0.3$ \\
\hline 44 & $19.9 \pm 0.2$ & $15.2 \pm 0.3$ & $12.9 \pm 0.2$ & $5.8 \pm 0.1$ \\
\hline 60 & $14.1 \pm 0.1$ & $14.0 \pm 0.5$ & $13.5 \pm 0.3$ & $0.6 \pm 0.01$ \\
\hline 70 & $23.9 \pm 0.3$ & $26.8 \pm 0.7$ & $21.9 \pm 0.9$ & $3.5 \pm 0.05$ \\
\hline 86 & $14.7 \pm 0.2$ & $8.4 \pm 0.1$ & $7.6 \pm 0.1$ & $1.4 \pm 0.02$ \\
\hline Totals & 109 & 100.7 & 81.8 & 18.3 \\
\hline
\end{tabular}

Further analysis was conducted in order to identify the domains on which the FN is adsorbed. The relative intensities of characteristic PS and PI ion peaks after FN adsorption on PS, PI and PS- $b$-PI copolymer films were collected. The ion peak at $\mathrm{m} / \mathrm{z}=68 \mathrm{u}$ has been removed from consideration because FN also provides strong intensities at this value from a hydrogen-carbon fragment. After FN adsorption, this will affect the PI's analysis by SIMS. 
Table 2 presents a comparison of the summed RPI of the PI and PS characteristic peaks before and after FN adsorption. The idea behind this analysis is that preferential protein adsorption will cause a decrease in the yield of the polymer domains, as protein will cover the domain surface. The yield from the other block, however, should not change if there is no adsorption on it. The magnitude of the drop in the summed RPI for a particular polymer block is assumed to be proportional to the fraction of its surface covered by adsorbed protein. As PS and PI have similar chemical compositions, they do not have unique SIMS peaks, but peaks were identified in which the relative peak intensity is strong for one polymer but not the other. ${ }^{33}$ Semi-quantitative analysis is therefore possible.

For the PI homopolymer film, the RPI of the characteristic PI peaks decrease by only about $25 \times 10^{-3}$ after the FN adsorption, which is a relatively small change. For the samples in the left three columns in Table 2, all RPIs of characteristic PI peaks decrease or increase only slightly after the FN adsorption. These negligible changes of RPI value imply that very few PI domains are covered by FN molecules. On the contrary, the RPIs of PS after FN adsorption decrease greatly for every sample that has a PS component. After FN adsorption, the PS's RPI for the PS homopolymer is decreased by $126.8 \times 10^{-3}$. For the $17.7 \mathrm{~nm}$ PS(45)- $b$-PI(46) film and the $17.8 \mathrm{~nm}$ PS(65)- $b$-PI(26) film, the RPI values for PS are both $c a .30 \times 10^{-3}$ after FN adsorption, having decreased by $47.2 \times 10^{-3}$ and $89.1 \times 10^{-3}$, respectively. The amount of FN adsorption on the PS block, as gauged by the RPI decrease, is found to be proportional to the fraction of PS blocks at the polymer film surface. 
Table 2 Relative intensity changes of PS and PI ion peaks after FN adsorption.

\begin{tabular}{|c|c|c|c|c|}
\hline & PS & $\begin{array}{c}\text { PS(65)- } b \text {-PI(26) } \\
17.8 \mathrm{~nm}\end{array}$ & $\begin{array}{c}\text { PS(45)- } b \text {-PI(46) } \\
17.7 \mathrm{~nm}\end{array}$ & PI \\
\hline \multicolumn{5}{|c|}{ Poly(isoprene) peaks $\left(\times 10^{-3}\right)$} \\
\hline Before FN Ads. & 9.0 & 17.6 & 85.0 & 201.9 \\
\hline After FN Ads. & 11.8 & 28.7 & 81.9 & 176.2 \\
\hline Difference & 2.8 & 11.1 & -3.1 & -25.7 \\
\hline \multicolumn{7}{|c|}{ Poly(styrene) peaks $\left(\times 10^{-3}\right)$} \\
\hline Before FN Ads. & 182.8 & 122.0 & 76.5 & 37.1 \\
\hline After FN Ads. & 56.0 & 32.9 & 29.3 & 29.8 \\
\hline Difference & -126.8 & -89.1 & -47.2 & -7.3 \\
\hline
\end{tabular}

The complementary use of AFM and SIMS reveals that the FN selectively adsorbs on the PS domains rather than on the PI domains on copolymer surfaces. The two-dimensional PS- $b$-PI templates have been used to form stable, well-organized FN nanopatterns. The results obtained for FN tell a similar story as previously found with BSA adsorption. ${ }^{33}$ Taken together, the results indicate that the PS- $b$-PI hard-soft templates can selectively adsorb a variety of proteins (not only BSA). In the following work, FN layers adsorbed on two control surfaces (a glass coverslip or on a flat, PS homopolymer film) and on nanopatterned surfaces (both stripe-like and ringlike patterns) were used to explore the influence of the nanopattern shape and the spacing of FN-ligand on cell adhesion functions.

\section{Cell adhesion analysis by confocal microscopy}

$\mathrm{CHO}$ cells following one hour of incubation on the control and on the nanopatterned FN on glass substrates was examined by confocal laser scanning microscopy. In Fig. 2, we show images of double-stained CHO cells. The red areas are DRAQ5-stained CHO cell nuclei and the green areas are phalloidin-stained actin. 
It is evident that the cell density on the ring-like FN nanopattern is higher than on the other three FN substrates.
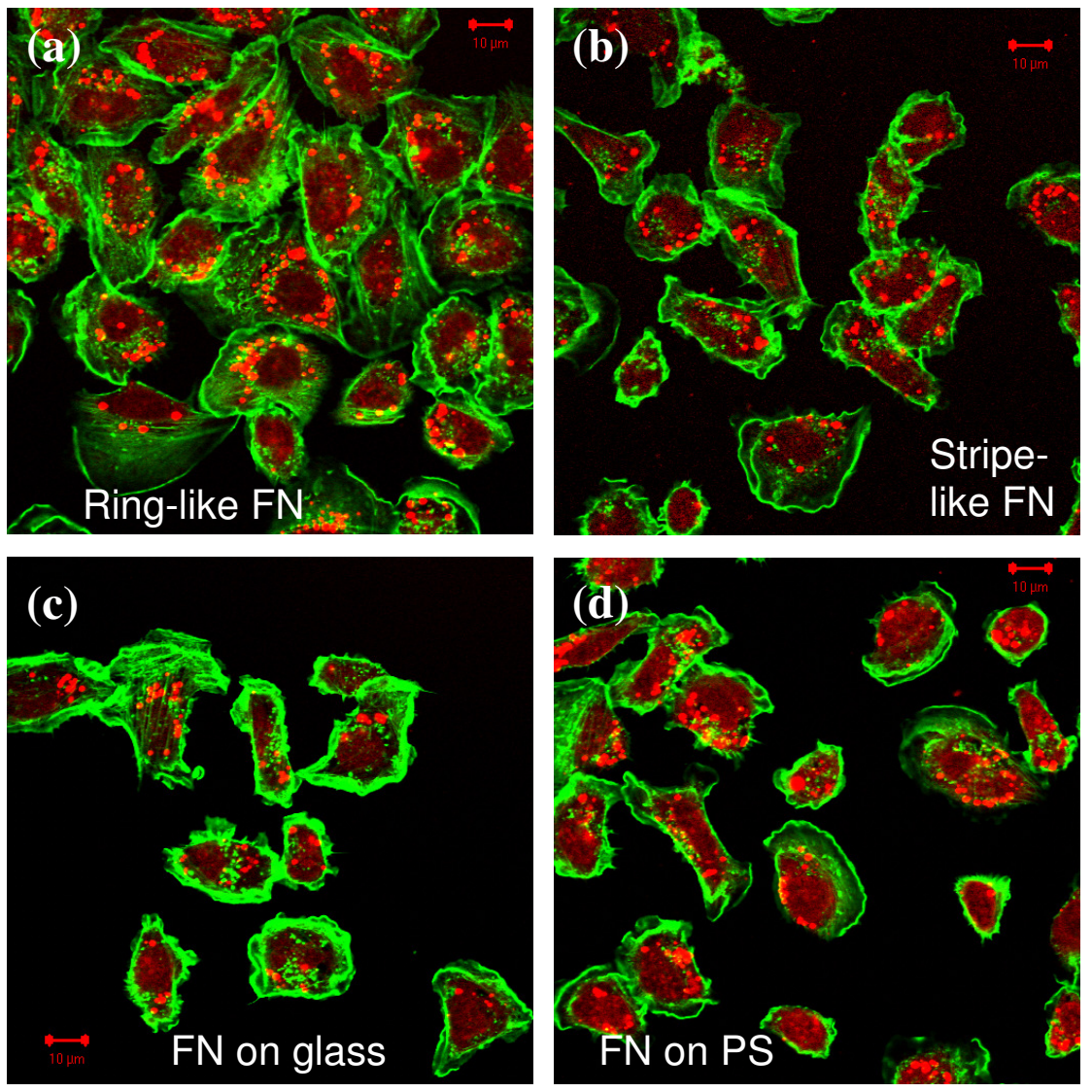

Fig. 2 Confocal microscopy images with nuclear (red) and actin (green) staining, showing CHO cell adhesion on different FN substrates: (a) ring-like FN nanopattern with $c a .50 \mathrm{~nm}$ domain spacing, (b) stripe-like FN nanopattern with $c a .12 \mathrm{~nm}$ domain spacing, (c) homogeneous FN surface on glass as a control surface, and (d) a homogeneous FN surface on pure PS as a control surface. The red scale bar in each image is $10 \mu \mathrm{m}$. The white text describes the underlying FN surface structures before cell adhesion.

The confocal images in Fig. 2 are representative of what was found in many observations. In each experiment, five confocal images were obtained from each of four different samples of the same type of template. The cell number density of 
attached cells and the percentage area of coverage by the spreading cells were determined from the images using Image $\mathbf{J}$ software. The entire experiment was repeated a second time, so that in total 40 images from eight samples of the same template type were analysed. The mean $\mathrm{CHO}$ cell densities are presented for each template type in Fig. 3, and the error bars represent the standard deviations obtained from analysis of the 40 images. The adhesion cell densities on the two control surfaces (FN on glass and FN on PS) and on the stripe-like FN surface are in the range between 400 and 500 cells $/ \mathrm{mm}^{2}$. On the other hand, the cell density on the ring-like FN pattern obtained on the PS(45)- $b$ - $\mathrm{PI}(46)$ template is $c a .750$ cells $/ \mathrm{mm}^{2}$, which is $50 \%$ more than obtained for the other three samples. In addition to the different $\mathrm{CHO}$ cell densities, the fraction of the surface covered by the cells is also different (Fig. 3). The cell coverage on the ring-like FN surface is $65 \pm 22 \%$, which means that in an image area, the majority of the FN surface is covered by attached cells. This number is double the percentage of other three FN surfaces. This result indicates that the ringlike FN nanopattern surface with a 50-nm domain spacing can increase the cell adhesion in the initial adhesion stage (i.e. after one hour of incubation).

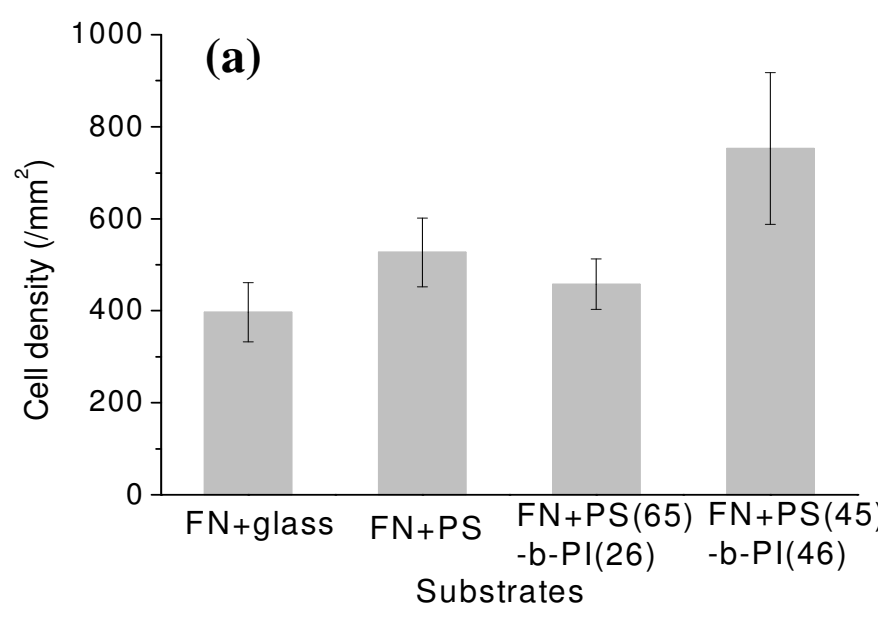




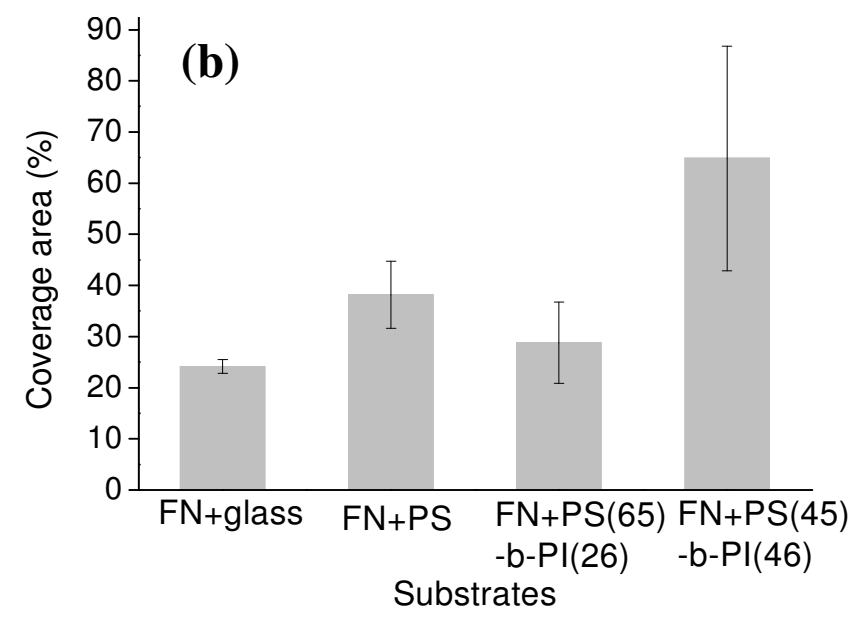

Fig. 3 (a) CHO cell densities on four different substrates with pre-adsorbed FN. (b) Area percentage covered by $\mathrm{CHO}$ cells after adhesion and spreading for $1 \mathrm{hr}$ on the four FN-coated substrates.

The actin cytoskeleton structure is difficult to observe in the double-stained images presented in Fig. 2. However, Fig. 4 shows images of the cells with actin staining on the four FN substrate types. It is apparent that the cells on the ring-like FN surface have attached and spread on the surface after only one hour. Almost all of the cells in the image are seen to be well spread. On the other three FN surfaces, however, some cells (identified by the blue arrows) have attached but have not begun to spread. The size of the adhered cells is also different, depending on the substrate. There is also a difference in cell shape, with fewer cells forming more elongated phenotype on the ring-like FN substrate than on the other three FN substrates.

Large bundles or fibres of actin are observed on both the control and the nanopatterned FN surfaces. We assume they link focal adhesions where the cell binds to the substrates. The development of actin fibres in $\mathrm{CHO}$ cells on ring-like FN substrates is very apparent. The spreading cells form abundant and highly-aligned actin fibres. The actin fibres in a single cell are in multiple directions. 

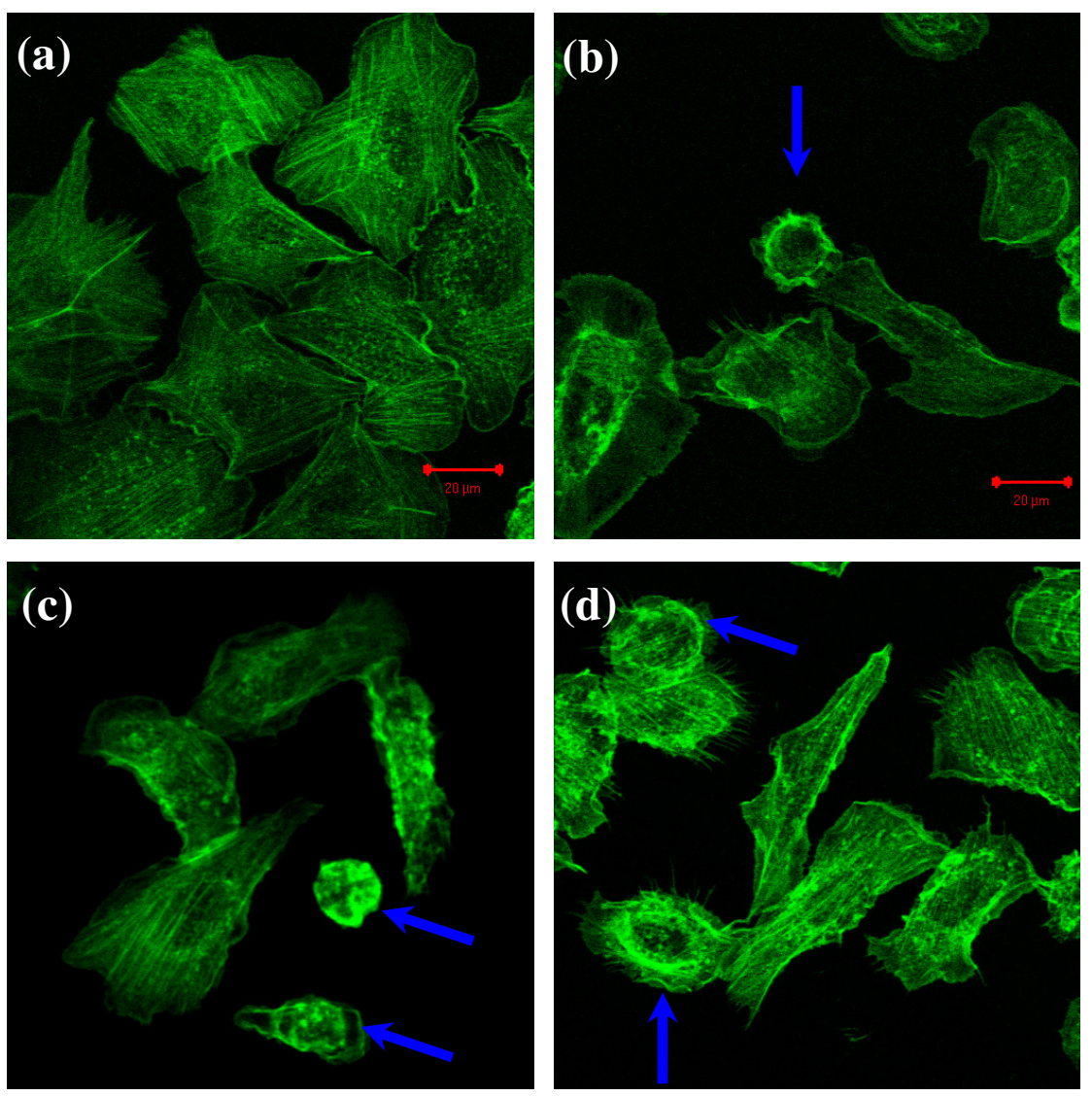

Fig. 4 Confocal images with actin staining to show $\mathrm{CHO}$ cells on different substrates: (a) a ring-like FN nanopattern with $c a .50 \mathrm{~nm}$ domain spacing, (b) a stripe-like FN nanopattern with $c a .12 \mathrm{~nm}$ domain spacing, (c) a homogeneous FN surface on glass, and (d) a homogeneous FN surface on PS. The red scale bar is $20 \mu \mathrm{m}$. The blue arrows indicate cells that are not well spread.

While immobilized ECM proteins can be used to control the initial adhesion of cells on a substrate, most adsorbed ECM surfaces are unstable in the presence of cells and thus are only transiently defined. Cells can remodel surfaces on which they are attached over a time period as short as two hours. ${ }^{38}$ In our experiment, the cell interaction with the FN surface is only monitored for one hour. Compared with other FN substrates, the ring-like pattern increases coverage by the cells. Focal adhesions and related structures are major cellular sites responsible for cell-ECM attachment and adhesion-mediated signalling. The well-organized actin cytoskeleton reflects the 
strong cell interaction with substrates. It is apparent that the ring-like FN-ligand pattern with around $50 \mathrm{~nm}$ spacing can positively affect the cell attachment and spreading.

The conformation of the FN on our substrates is undoubtedly different to the conformation in vivo. $\mathrm{FN}$ is a large protein with several domains ${ }^{11}$ whose conformation will inevitably be affected by adsorption on copolymer templates. Nevertheless, the RGD motif and the surrounding residues are much smaller than the whole molecule, and can bind integrins. Earlier work has found good cell adhesion on $\mathrm{FN}^{25-28}$. In this previous work, the $\mathrm{FN}$ structure likewise would have differed from that in the ECM in vivo. Although our and others' nanopatterned FN surfaces are clearly different to the ECM in vivo, the FN is still expected to present the same binding motifs to the integrins as are present in FN in the ECM.

\section{Influence of FN nanopatterns on cell adhesion}

As can be seen in Fig. 3, the cell density and area percent of coverage on the ring-like FN surface have large standard deviations. We believe that the spread of values results from the cell adhesion behaviour being non-uniform on this substrate. Examples of optical images of cells on the ring-like FN surface, presented in Fig. 5, indeed show that the density and shape of adhered cells are not uniform across a patterned substrate. In some regions, the cell density is, high but in other regions, fewer cells are adsorbed on the substrates. Additional experiments, described next, explain the reasons for this variability. 

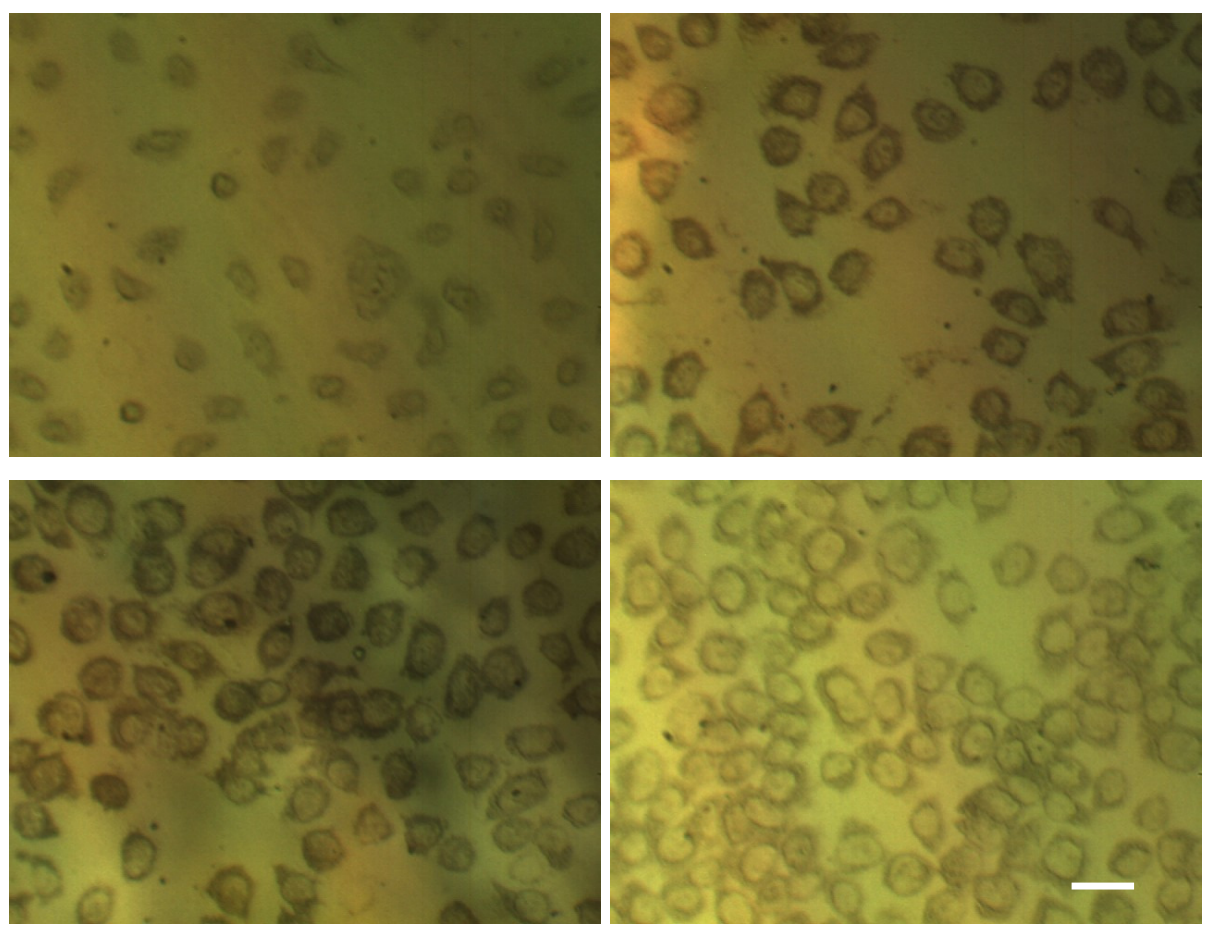

Fig. 5 Optical images of $\mathrm{CHO}$ cells after $1 \mathrm{~h}$ adhesion on the ring-like FN substrates for different areas on the same sample. All images are at the same magnification. White scale bar size is $40 \mu \mathrm{m}$.

Before cell culture, several FN-coated glass coverslips were divided into nine sub-areas and the relative hydrophilicity of every sub-area was determined by water contact angle analysis. Here, the water contact angle is not of direct interest, but rather it is useful to determine it in order to correlate with the FN structures, as determined by AFM.

Measurements of cell densities were collected from two different samples in which a PS(45)- $b$-PI(46) copolymer film on a glass substrate had been templated with FN. The mean cell densities were determined in each of the nine different sub-areas through analysis of several images obtained from that sub-area. Owing to small differences in how the surfaces were rinsed with buffer solution and DI water, the distribution of water contact angles on the two surfaces differ. Furthermore, there is 
variability in the water contact angle across each substrate, which results in a spread of contact angles. Figure 6 shows values of the mean cell density in a sub-area as a function of the mean contact angle in its sub-area. The error bars on the densities represent the standard deviation of the measurements from the images in a sub-area corresponding to the particular water contact angle. (In the cases in which the mean contact angle for a sub-area was within $1^{\circ}$ of the value for one or more other sub-area, a mean value for all those sub-areas was calculated, and the mean cell density for those sub-areas is reported in Figure 6.)

There is a clear trend showing that more cells adhere to the areas with a larger water contact angle. The maximum mean cell density on the ring-like FN pattern on PS(45)- $b$-PI(46), which is $680 \pm 103 \mathrm{~mm}^{-2}$, is found in a sub-area with a high water contact angle $\left(65^{\circ}\right)$. The sub-area with the lowest water contact angle $\left(21^{\circ}\right)$ has a mean cell density of only $118 \pm 29 \mathrm{~mm}^{-2}$.

For the FN surfaces on the PS(65)- $b$-PI(26)) template, data points were likewise obtained from two samples. The peak mean cell density on this stripe-like FN substrate is $470 \pm 65 \mathrm{~mm}^{-2}$ and was found in a sub-area with a high water contact angle, whereas the area with a low water contact angle $\left(42^{\circ}\right)$ has a mean cell density of only $70 \pm 13 \mathrm{~mm}^{-2}$. 


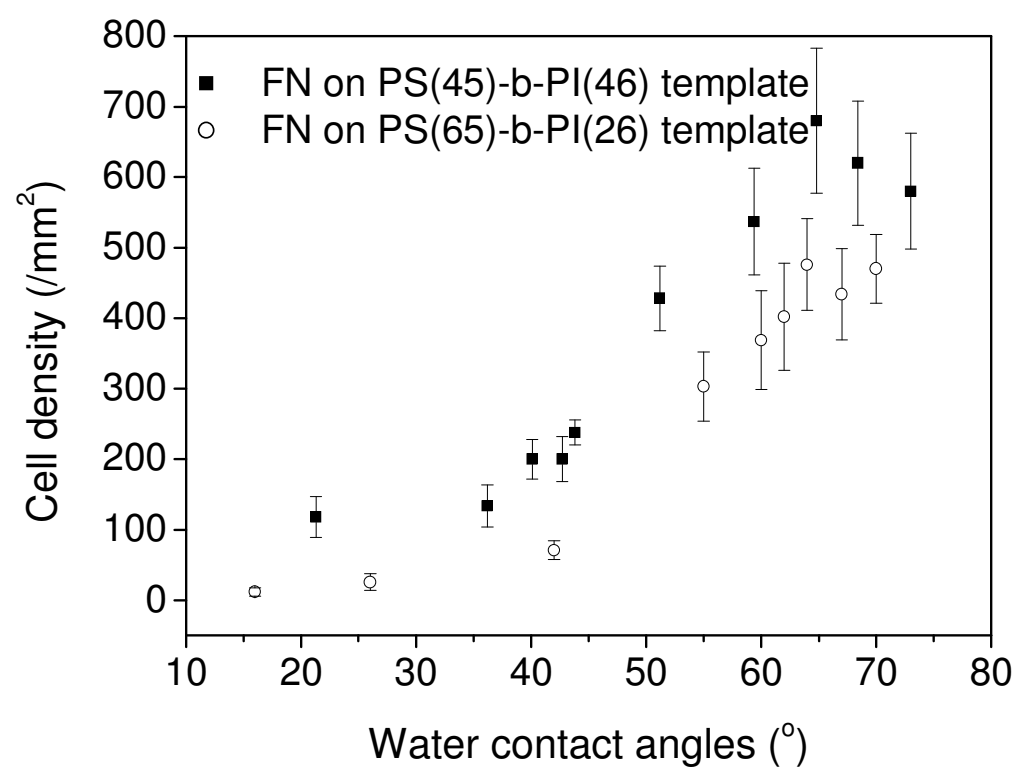

Fig. 6 Adhered cell density as a function of the water contact angle on nanopatterned FN substrates. Filled square symbols represent cells on a $\mathrm{FN}+\mathrm{PS}(45)-b-\mathrm{PI}(46)$ template; and open round symbols are for cells on a FN+PS(65)-b-PI(26) template.

FN is hydrophilic, and the PS-PI copolymer is hydrophobic (with a water contact angle of $110^{\circ}$ ). The variability in the water contact angles of the patterned FN surfaces might therefore be expected to be explained by variability in the patterns. Representative FN patterns on a PS(45)- $b$-PI(46) template (on Si) are shown in Fig. 7. Although the FN on the same PS(45)-b-PI(46) template forms ring-like patterns in every sub-area, the ring sizes are variable across the surface. The mean FN ring diameters were calculated using commercial software (Nova, NT-MDT). For each of the images shown in Figure 7 , the ring diameters are reported along with the corresponding mean contact angle in the caption. In some areas, the ring size approximately matches the size of the underlying copolymer template (Fig. 7a), but there are other examples in which the ring sizes are larger than the copolymer pattern size (Figures $7 \mathrm{~b}$ and $7 \mathrm{c}$ ). When the $\mathrm{FN}$ ring size is much bigger, the underlying copolymer dot-like structure is clearly apparent in the AFM images (Figure 7d). 
Larger FN ring patterns correspond to less hydrophilic surfaces (i.e. a higher water contact angle).
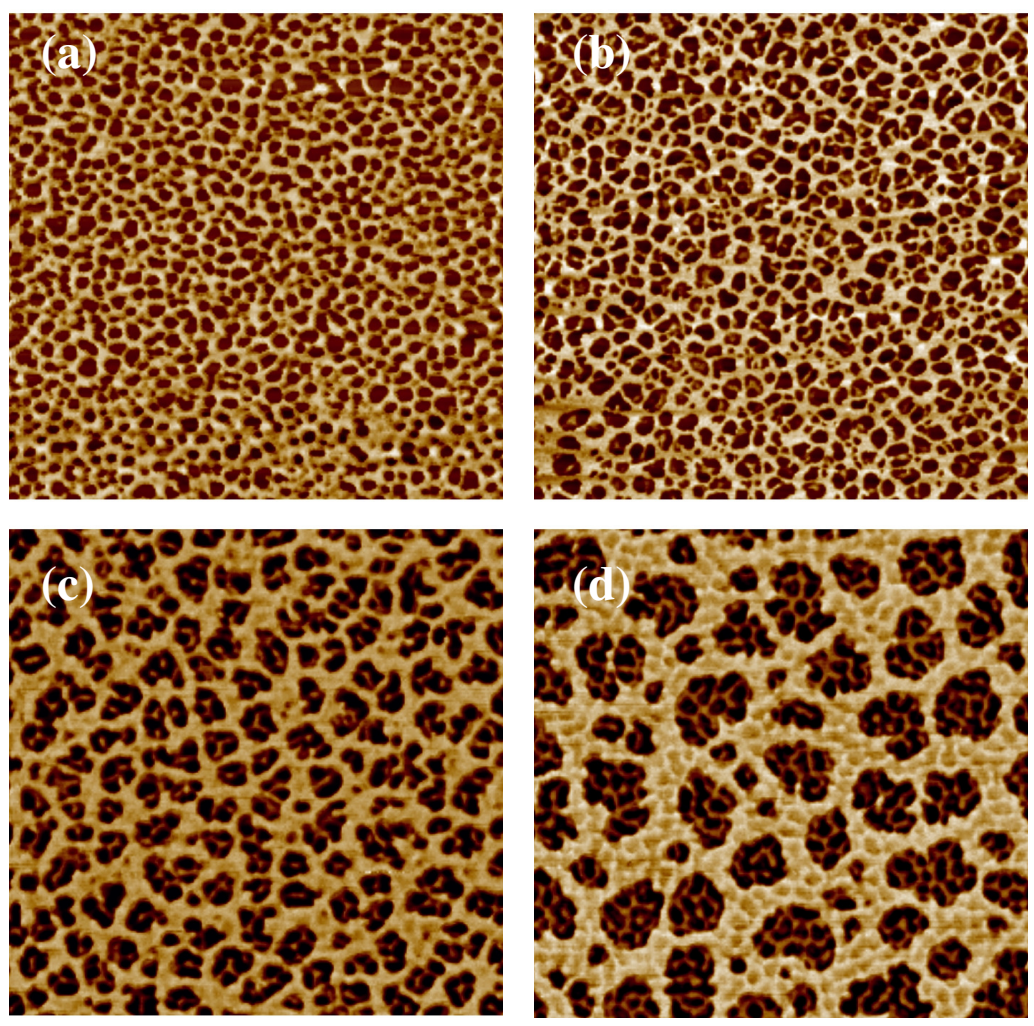

Fig. 7 AFM phase images showing different sizes of FN ring structures on a PS(45)$b$-PI(46) template. As the diameter of the FN ring size increases, the water contact angle also increases: (a) FN ring diameter of $55 \mathrm{~nm}$ and contact angle of $64.9^{\circ}$; (b) 86 $\mathrm{nm}$ and $68.5^{\circ}$; (c) $125 \mathrm{~nm}$ and $73.4^{\circ}$; and (d) $180 \mathrm{~nm}$ and $77.3^{\circ}$. All images are $2 \mu \mathrm{m}$ $\times 2 \mu \mathrm{m}$ in area.

Our previous work ${ }^{33}$ found that BSA molecules were adsorbed on PS- $b$-PI templates and formed very stable ring-like structures. There was no ring size variability across the sample surface, and the ring size matched the copolymer template in all areas. We speculate that the much bigger size of the FN molecules prevents them from adapting to structures with fine features. Obtaining more uniform templates is an objective of future research. 
Figure 8 reveals that the water contact angle and the FN ring diameter have a positive linear relationship, except for the lowest ring diameter $(45 \mathrm{~nm})$. This linear trend is reasonable because the larger that the FN ring size is, then the more that the copolymer components are exposed to the interface, as is indicated qualitatively in the AFM images (Fig. 7). The hydrophobicity of the copolymer then makes a greater contribution.

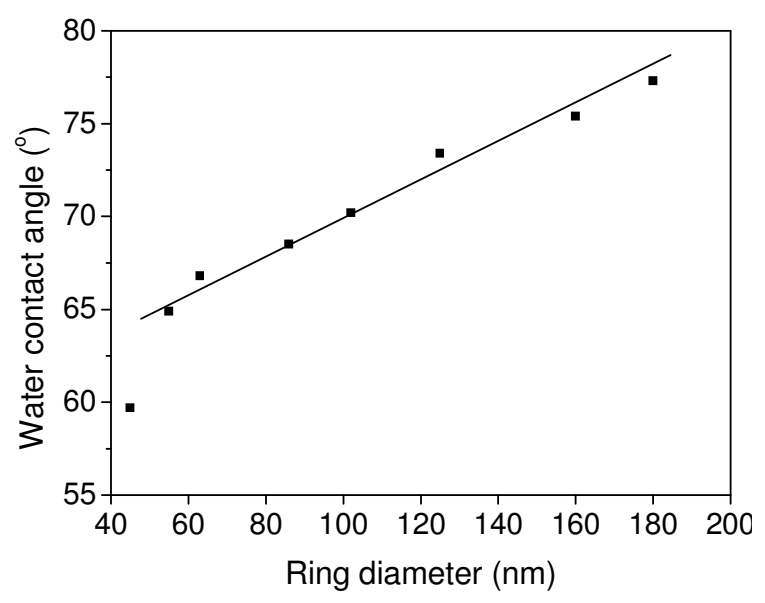

Fig. 8 Water contact angle as a function of FN ring diameter on PS(45)- $b$-PI(46) templates.

So far, it is apparent that there is a correlation between the cell adhesion density and the water contact angle. In turn, the water contact angle depends on the FN ring diameter. Combining these results, it can be concluded that the cell adhesion correlates with the FN ring diameter. The data in Figures 6 and 8 were correlated via their water contact angle values and were re-plotted in Fig. 9a to show how the cell density varies with the FN ring diameter. This graph shows that there is a higher cell density when there is a ring size greater than about $50 \mathrm{~nm}$. The cell density does not vary with FN ring-size above $50 \mathrm{~nm}$. The sub-areas with water contact angles lower than $45^{\circ}$ are all ascribed to complete FN coverage, and the ring size is given a value 
of $0 \mathrm{~nm}$.

The fractional coverage of FN on each of the surfaces was calculated using Image $\mathbf{J}$ software to analyse the AFM images (see Figure 7 for example images). The areas on which there was dense FN coverage, and which had a water contact angle lower than $45^{\circ}$, were ascribed to $100 \%$ FN coverage. Fig. $9 \mathrm{~b}$ indicates that there is a higher cell density when the FN coverage is less than ca. $85 \%$. Blanket coverage by FN correlates with a lower cell density. (Note that in the absence of adsorbed FN (0\% coverage) preliminary experiments found that cell densities were exceedingly low. The surfaces of hydrophobic polymers are normally treated ${ }^{34-36}$ to make them suitable for cell cultures.)
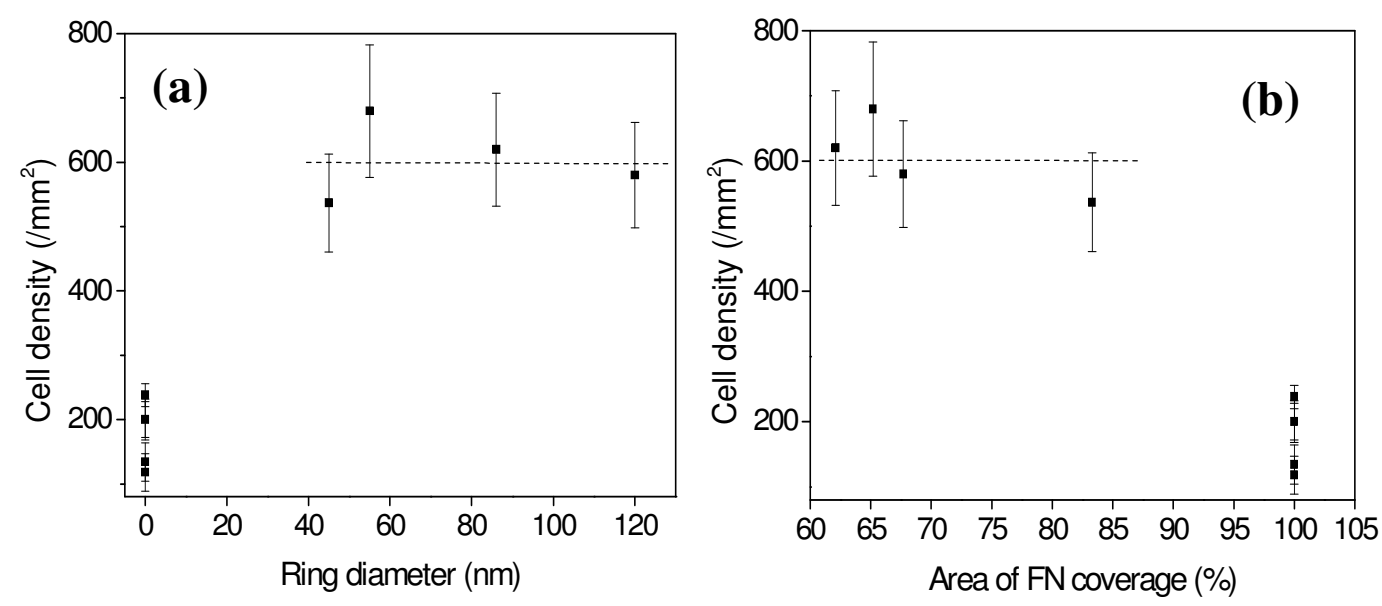

Fig. 9 The relationships of (a) cell density with FN ring diameter, and (b) cell density with the area coverage by FN on a PS(45)- $b$-PI(46) template.

Fabricated nanopatterns of biological molecules, such as adhesive peptides, are widely used to induce specific cellular responses dependent on cell adhesion. Maheshwari et al. ${ }^{39}$ functionalized star-shaped polymers with RGD-containing peptide on a background surface to which cells do not adhere, to achieve a controlled surface density and local spatial distribution of the peptide. The RGD motif is present 
in fibronectin. When the RGD peptide was presented in clusters of at least five peptides per star, but not in the case of a random single RGD peptide per star, cells developed well-formed actin stress fibres and mature focal adhesions. Other research ${ }^{40}$ indicates that higher ligand clusters and higher ligand densities reinforce the cell adhesion. These studies lead to the hypothesis that cell spreading might be dependent on a critical density of integrin ligands on the substrate producing an integrin cluster that is dense enough to recruit focal adhesion and cytoskeleton proteins. Such a local integrin ligand density could be critical for the initiation of a mature and stable focal adhesion.

Although the local concentration of FN on the substrates is not known in our experiments, the FN solution concentrations are the same for every polymer substrate. The FN molecules are randomly distributed on glass and PS surfaces. But on the PS(45)- $b$-PI(46) copolymer template, the FN forms ring-like nanopatterns. The spacing induces more FN localisation on the pattern of PS blocks, and the FN density on these areas is increased. This high local density of adhesive FN-ligands perhaps enhances the integrin clustering and the focal adhesion. The cells spread very well after seeding for one hour on the ring-like pattern and form abundant actin stress fibres. The effect of the shape of the FN patterns (e.g. ring-like, square, or elliptical, etc.) has not been investigated in our experiments, but it could potentially be sensed by the cells and thus could also contribute to the cell adhesion and spreading. In contrast, the stripe-like FN nanopattern with a smaller spacing cannot significantly improve the FN density in local areas. The cell adhesion behaviour on the stripe-like patterned substrate is similar to the adhesion on homogeneous substrates. 


\section{Conclusions}

In this work, FN nanopatterns were created by adsorption on copolymer thin film templates. The complementary use of AFM and ToF-SIMS showed that protein preferentially adsorbs on PS blocks rather than on PI blocks. This preferential adsorption induces FN patterns resembling the underlying block copolymer surface morphology. The use of self-assembled PS- $b$-PI has been found to provide a precise, two-dimensional template for the nanopatterning of FN and previously BSA.

The ring-like FN nanopattern on PS(45)- $b$-PI(46) substrate increases the cells' adhesion compared with the cells on homogeneous FN surfaces and patterns on PS(65)- $b$-PI(26). The adhered cell density and percentage area of coverage on the ring-like FN surface is higher than on the other three substrates. The ring-like pattern also develops more actin fibres, cell spreading, and focal adhesion. Cell adhesion is high when the FN ring size is $>50 \mathrm{~nm}$ and when the surface coverage of $\mathrm{FN}$ is $<c a$. $85 \%$. The increasing cell adhesion on ring-like nanopattern is attributed to a high local FN density on the ring areas. It is proposed that a high FN-ligand density increases the integrin clustering and encourages stable focal adhesion.

From a practical standpoint, the FN templating method provides a new way to increase cell adhesion to surfaces for applications in tissue engineering. Compared to techniques of lithography to create FN nanopatterns, our method makes use of the self-assembly of templates, and hence it is simpler and faster. The process is applicable to large areas on a variety of solids. In principle, the entire area of cell culture dishes could be coated with FN nanopatterns self-assembled on polymer templates. There is a need to evaluate the efficiency of this method in the future by performing cell adhesion and cell morphology studies on "hard-to-culture" cells, 
primary cells or stem cells, which require the substrate to be coated with an ECM material, such as fibronectin or collagen. ${ }^{41}$ There remains a need to decrease the variability in the FN patterns on the templates to achieve the desired pattern size across the entire surface. The use of blends of homopolymers and diblock or triblock copolymers opens up the possibility of creating templates with a wider range of pattern size and geometries, provided that the PI wetting layer is avoided or removed.

\section{Acknowledgements}

D.L. acknowledges a scholarship from the Kwan Trust (University of Surrey) and funding from Angiotech BioCoatings. C.A.C.A. acknowledges the Ministry of Higher Education (MOHE) Malaysia and the University of Putra Malaysia for providing financial support for her $\mathrm{PhD}$ studies. Dr. Steven Hinder (University of Surrey) assisted with the acquisition of the ToF-SIMS data. We acknowledge useful discussions of the data analysis with Prof. John Watts and Ms. Naoko Sano (University of Surrey) and chemical laboratory assistance from Mrs. Violeta Doukova (University of Surrey). We gratefully acknowledge use of the confocal microscope facility in the laboratory of Dr. Alexandra Bermudez-Fajardo and assistance from Rebecca Holland. We also acknowledge use of the cell culture laboratory of Dr. Kate Plant at the University of Surrey.

\section{References}

\footnotetext{
${ }^{1}$ B. M. Gumbiner, Cell, 1996, 84, 345.

${ }^{2}$ H. Alam, D. Kim, E. Brun, J. Tiollier, H. Provido and J. Kirkpatrick, Surgery, 1998, 124, 87.

${ }^{3}$ L. G. Griffith, Ann. NY Acad. Sci., 2002, 961, 83.
} 
${ }^{4}$ Z. Mostafavi-Pour, J. A. Askari, S. J. Parkinson, P. J. Parker and M. J. Humphries, J. Cell Biol., 2003, 161, 155.

${ }^{5}$ D. J. Sieg, C. R. Hauck and D. D. Schlaepfer, J. Cell Sci., 1999, 112, 2677.

${ }^{6}$ S. K. Sastry, M. Lakonishok, S. Wu, T. Q. Truong, A. Huttenlocher, C. E. Turner, and A. F. Horwitz, J. Cell Biol., 1999, 144, 1295.

${ }^{7}$ D. O. Meredith, G. R. Owen, I. Gwynn and R. G. Richards, Exp. Cell Res., 2004, 293, 58.

${ }^{8}$ K. K. Wary, F. Mainiero, S. J. Isakoff, E. E. Marcantonio and F. G. Giancotti, Cell, 1996, 87, 733.

${ }^{9}$ E. A. C. Almeida, D. Ilic, Q. Han, C. R. Hauck, F. Jin, H. Kawakatsu, D. D. Schlaepfer and C. H. Damsky, J. Cell Biol., 2000, 149, 741.

${ }^{10}$ M. Scatena, M. Almeida, M. L. Chaisson, N. Fausto, R. F. Nicosia and C. M. Giachelli, J. Cell Biol., 1998, 141, 1083.

${ }^{11}$ B. Alberts, A. Johnson, J. Lewis, M. Raff, K. Roberts and P. Walter. Molecular Biology of the Cell. New York, NY, Garland Science, 2002, 1616.

${ }^{12}$ K. Burridge and M. Chrzanowska-Wodnicka, Annu. Rev. Cell Dev. Biol., 1996, 12, 463.

${ }^{13}$ B. Geiger, A. Bershadsky, R. Pankov and K. M. Yamada, Nat. Rev. Mol. Cell Biol., $2001,2,793$.

${ }^{14}$ M. Arnold, E. A. Cavalcanti-Adam, R. Glass, J. Blummel, W. Eck, M. Kantlehner, H. Kessler and J. P. Spatz, ChemPhysChem, 2004, 5, 383.

${ }^{15}$ I. Singer, S. Scott, D. W. Kawka, D. M. Kazazis, J. Gailit and E. Ruoslahti, J. Cell Biol., 1998, 106, 2171.

${ }^{16}$ B. G. Keselowsky, D. M. Collard and A. J. Garcia, J. Biomed. Mater. Res. Pt A 2003, 66a, 247. 
${ }^{17}$ D. E. Discher, P. Janmey and Y. L. Wang, Science, 2005, 310, 1139.

${ }^{18}$ A. S. Andersson, F. Backhed, A. von Euler, A. Richter-Dahlfors, D. Sutherland and B. Kasemo, Biomaterials, 2003, 24, 3427.

${ }^{19}$ L. Y. Koo, D. J. Irvine, A. M. Mayes, D. A. Lauffenburger and L. G. Griffith. J. Cell Sci., 2002, 115, 1423.

${ }^{20}$ A. S. Curtis and C. D. Wilkinson. J. Biomater. Sci. Polym. Ed., 1998, 9, 1313.

${ }^{21}$ I. Y. Tsai, M. Kimura, R. Stockton, J. A. Green, R. Puig, B. Jacobson and T. P. Russell, J. Biomed. Mater. Res. Pt. A, 2004, 71a, 462.

${ }^{22}$ C. J. Bettinger, R. Langer and J. T. Borenstein, Angew. Chem. Int. Ed., 2009, 48, 5406.

${ }^{23}$ E. A. Cavalcanti-Adam, A. Micoulet, J. Blummel, J. Auernheimer, H. Kessler and J. P. Spatz, Eur. J. Cell Biol., 2006, 85, 219.

${ }^{24}$ D. Lehnert, B. Wehrle-Haller, C. David, U. Weiland, C. Ballestrem, B. A. Imhof and M. Bastmeyer, J. Cell Sci., 2004, 117, 41.

${ }^{25}$ C. Kuschel, H. Steuer, A. N. Maurer, B. Kanzok, R. Stoop and B. Angres, Biotechniques, 2006, 40, 523.

${ }^{26}$ D. Pesen and D. B. Haviland. ACS Appl. Mater. Interfaces, 2009, 1, 543.

${ }^{27}$ J. H. Slater and W. Frey. J. Biomed. Mater. Res. Pt. A, 2008, 87a, 176.

${ }^{28}$ M. Arnold, M. Schwieder, J. Blummel, E. A. Cavalcanti-Adam, L. G. Monica, H. Kessler, B. Geiger and J. P. Spatz, Soft Matter, 2009, 5, 72.

${ }^{29}$ J. D. Hoff, L. J. Cheng, E. Meyhofer, L. J. Guo and A. J. Hunt, Nano. Lett., 2004, 4, 853 .

${ }^{30}$ K. B. Lee, S. J. Park, C. A. Mirkin, J. C. Smith and M. Mrksich, Science, 2002, 295, 1702.

${ }^{31}$ Y. Chang, Y. S. Ahn, H. T. Hahn and Y. Chen, Langmuir, 2007, 23, 4112. 
${ }^{32}$ R. Glass, M. Arnold, J. Blummel, A. Kuller, M. Moller and J. P. Spatz, Adv. Funct. Mater., 2003, 13, 569.

${ }^{33}$ D. Liu, T. Wang, and J. L. Keddie, Langmuir, 2009, 25, 4526.

${ }^{34}$ K.L. Mittal, and A. Pizzi Adhesion promotion techniques: Technological applications. New York, M. Dekker, 1999, 139-235.

35 K.H. Siow, L. Britcher, S. Kumar, H.J. Griesser, Plasma Process Polym. 2006, 3, 392.

${ }^{36}$ A. Meyer-Plath, K. Schröder, B. Finke, A. Ohl, Vacuum, 2003, 71, 391.

37 www.hpacultures.org.uk/collections/ecacc.jsp

${ }^{38}$ C. Roberts, C. S. Chen, M. Mrksich, V. Martichonok, D. E. Ingber and G. M. Whitesides, J. Am. Chem. Soc., 1998, 120, 6548.

${ }^{39}$ G. Maheshwari, G. Brown, D. A. Lauffenburger, A. Wells and L. G. Griffith, J. Cell Sci., 2000, 113, 1677.

${ }^{40}$ L. Y. Koo, D. J. Irvine, A. M. Mayes, D. A. Lauffenburger and L. G. Griffith, J. Cell Sci., 2002, 115, 1423.

41 J.R.W. Masters, Animal cell culture: A practical approach. Oxford, Oxford University Press, 2000. 